\title{
The Analysis of Inter-Island Trade Data Collection
}

\author{
Dwi Wahyuniarti Prabowo \\ Center for Domestic Trade Analysis \\ Trade Research and Development Agency, Ministry of Trade \\ Jakarta, Indonesia \\ dwi.wahyuniarti@kemendag.go.id
}

\author{
Aditya Priantomo \\ Center for Domestic Trade Analysis \\ Trade Research and Development Agency, Ministry of Trade \\ Jakarta, Indonesia \\ adityapriantomo@gmail.com
}

\begin{abstract}
Inter-island trade data becomes one of the bases to formulate policy recommendations to maintain price stability and reduce price disparity across regions in Indonesia. However, inter-island trade data still not well recorded and managed. The purpose of this study is to measure the performance of the inter-island trade data collection process by Ministry of Trade and to identify problems of data collection. Important Performance Analysis (IPA) is utilized to measure the performance of inter-island trade data collection and Likert Scale is used for problems identification. The study found that in inter-island trade data collection terms of importance is at the level of 3,25 . While in terms of performance is at the level of 4,35 . It can be interpreted that the level of performance is better than the level of importance, so in other words the process of inter-islands data collection is relatively effective. Meanwhile, the main problem in interisland trade data collection are the lack of coordination between Ministries/Agencies, the policy that has not been well socialized, and there is no comprehensive method of interisland trade data collection. For this reason, coordination and synchronization and further agreement is needed to develop a comprehensive inter-island trade database, and creating method of data collection.
\end{abstract}

\section{Keywords-Inter-island Trade, Database, Trade}

\section{INTRODUCTION}

The regulation of inter-island trade activities is mandated by Law number 7 of 2014 about Trade. The regulation is directed at maintaining a balance between surplus regions and minus regions; securing the distribution of trade restricted goods; develop marketing of superior products of each region; providing inter-island trade facilities and infrastructure; prevent the entry and circulation of contraband goods in the country; prevent smuggling of goods abroad; and eliminate inter-island trade barriers.

Data collection on inter-island trade is important, which is one of the bases in providing policy recommendations to reduce price disparities between regions. So far the data on inter-island trade is not well recorded so that it cannot provide an overview of the flow of goods between regions. Moreover, even though there are policies related to the recording of inter-island trade, there are still many interisland traders who have not reported regarding the manifest data. As of march 2018, 51 companies have reported their trade data (Directorate of Logistics, ministry of Trade, 2018) while Inter-Island Trade Information System (SIPAP) is still in development.
The purpose of this analysis is to measure the performance of the inter-island trade data collection process by Ministry of Trade and to identify the problems of data collection.

\section{MethodolOGY}

Qualitative descriptive analysis is used to identify mechanisms and problems in the implementation of interisland trade data collection combined with the Likert scale. Meanwhile, to answer the objective of the analysis of the effectiveness of inter-island trade data collection, the Importance Performance Analysis (IPA) approach was used.

\section{A. Importance Performance Analysis (IPA)}

This analysis method is usually used to measure the relationship between consumer perceptions and the priority of program quality improvement, also known as quadrant analysis (Brandt, 2000 and Latu and Everett, 2000). The IPA method has a display of analysis results that support performance improvement (Martinez, 2003). The IPA method can determine the degree of conformity, seen from the level of performance/implementation and expectations/ interests of stakeholders on the quality of the program. The level of conformity in this analysis can be seen from the level of performance and expectations of stakeholders on the quality of inter-island trade data collection using Importance Performance Analysis (IPA)

The IPA analysis is carried out through several stages, namely as follows:

\section{1) Stage 1}

In the first stage, identification of performance attributes of inter-island trade data was identified. Identification is carried out based on the results of discussion with stakeholders. These attributes are then arranged in a Likert scale scoring table which is then included in the questionnaire. Scoring based on Likert scale is shown in table I and table II.

TABLE I. LIKERT SCALE SCORING LEVEL OF PERFORMANCE IPA

\begin{tabular}{|c|c|}
\hline Choices & Score \\
\hline Very Poor & 1 \\
\hline Poor & 2 \\
\hline Acceptable & 3 \\
\hline Good & 4 \\
\hline Very Good & 5 \\
\hline
\end{tabular}


TABLE II. LIKERT SCALE SCORING LEVEL OF IMPORTANCE IPA

\begin{tabular}{|c|c|}
\hline Choices & Score \\
\hline Not Important & 1 \\
\hline Slightly Important & 2 \\
\hline Moderately Important & 3 \\
\hline Important & 4 \\
\hline Very Important & 5 \\
\hline
\end{tabular}

\section{2) Stage 2}

Determine the level of suitability between the level of importance and the level of performance of the quality of the attributes studied through a comparison of performance scores with importance scores. The formula used is as follows.

$$
\mathrm{Tki}=\frac{\mathrm{Xi}}{\mathrm{Yi}} \times 100 \%
$$

Information:

Tki = Level of Conformity

$\mathrm{Xi} \quad=$ Performance Assessment Score

$\mathrm{Yi} \quad=$ Importance Assessment Score

Testing Criteria:

- Tki $<100 \%$; The Program has not been effective

- Tki $>=100 \%$; The Program has been effective

\section{3) Stage 3}

Calculate the average rating of importance and performance for each attribute item using the formula:

$$
\overline{X i}=\frac{\sum_{i=1}^{k} X i}{n}
$$

Information:

$\mathrm{Xi}=$ The weight of the average level of assessment of the performance attributes of- $\mathrm{i}$

$\mathrm{n} \quad=$ Total respondent

and

$$
\bar{Y}_{i}=\frac{\sum_{i=1}^{k} Y_{i}}{n}
$$

Information:

Yi $=$ The weight of the average level of assessment of the importance attributes of- $\mathrm{i}$

$\mathrm{n} \quad=$ Total respondent

\section{4) Stage 4}

Calculate the average rating of importance and performance for the entire attribute with the following formula:

$$
\overline{\overline{X i}}=\frac{\sum_{i=1}^{k} \overline{X i}}{n}
$$

Information:

$\mathrm{Xi} \quad=$ The weight of the average level of assessment of the performance attributes of- $i$

$\mathrm{n}$ $=$ Total attribute

and

$$
\overline{\overline{Y i}}=\frac{\sum_{i=1}^{k} \overline{Y i}}{n}
$$

Information:

$\mathrm{Yi}=$ The weight of the average level of assessment of the performance attributes of- $i$

$\mathrm{n} \quad=$ Total attribute

\section{5) Stage 5}

The results of the calculation of the average rating of importance and performance then obtained the weight of performance and importance of attributes and the average value of performance and importance, then the values are plotted into the Cartesian quadrant shown in figure 1. The value intersects perpendicular to the horizontal axis, that is, the axis that reflects the performance of the attribute $(\mathrm{X})$. The value intersects perpendicular to the vertical axis, that is, the axis that reflects the importance of the attribute (Y).

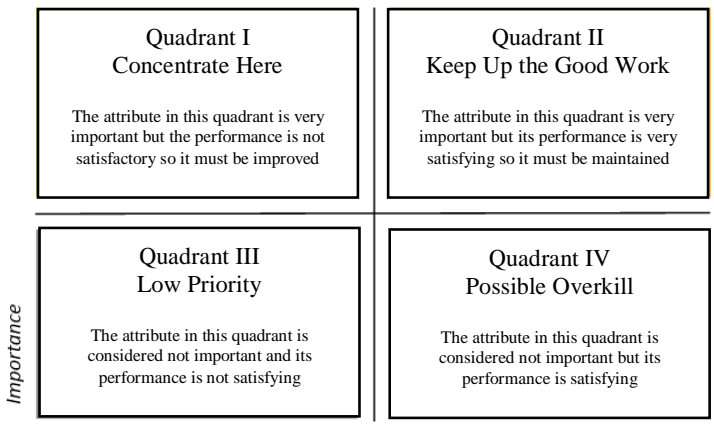

Performance

Fig. 1. Performance Quadrant Diagram of IPA

\section{B. Likert Scale}

Likert scale is used to measure perceptions of respondents regarding problems or inhibiting factors is carried out through interviews and discussion with stakeholders and then arranged in a questionnaire to be assessed by respondents.

Assessment or scoring of Likert scale on problems and inhibiting factors is carried out with a scale of five in the form of perceptual choices. The scores for each answer option are shown in table III.

TABLE III. LIKERT SCALE SCORING

\begin{tabular}{|c|c|}
\hline Choices & Score \\
\hline Not Important & 1 \\
\hline Slightly Important & 2 \\
\hline Moderately Important & 3 \\
\hline Important & 4 \\
\hline Very Important & 5 \\
\hline
\end{tabular}

The results of the respondent's answer are then calculated by the formula: 


\section{$\mathrm{T} \times \mathrm{Pn}$}

Information:

$\mathrm{T} \quad=$ Total number of respondents

Pn $=$ Choice of Likert score numbers

\section{RESULTS AND DiSCUSSION}

\section{A. Analysis of the Problems in Inter-island Trade Data Collection}

As shown in figure 2, the main factor that inhibits interisland trade data collection is first, coordination between Ministries / Institutions in inter-island trade data collection is not good. This is become a problem because data collection on the flow of goods or trade between islands is carried out by different Ministries and Institutions with different objectives. Therefore, every Ministries and Institutions have its own concerned in carrying out data collection. If coordination is good, then the data in each Ministries and Institutions will be more easily to harmonized so that better inter-island trade data can be obtained.

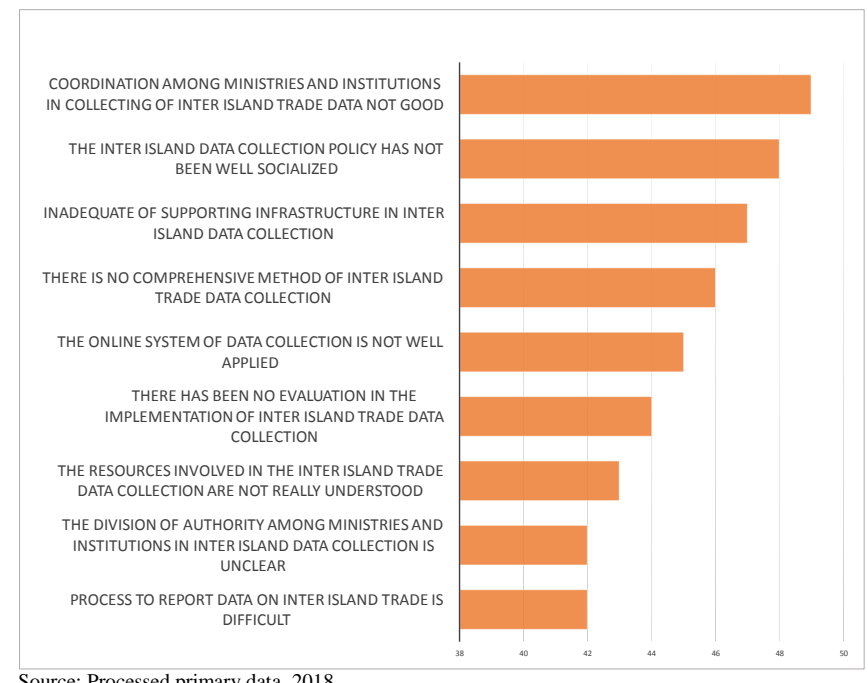

Fig.2. The Inhibiting Main Factors of Data Collection Inter-island Trade.

The next problem is the inter-island trade data collection policy has not been well socialized. Problems were found with inter-island trade data collection by reporting domestic manifests through Integrated Licensing Information System (SIPT). Trader are still not well socialized and feel objected. Reporting online through SIPT which must register first is considered a hassle by trader. In addition, not all trader made domestic manifests. Trading companies usually hand over the making of manifest domestic to logistic service companies or forwarders, but logistics services companies based on Permendag 29 of 2017 are not obliged to report domestic manifest through SIPT. Logistics service companies report the domestic manifest to the Ministry of Transportation through Inaportnet or Simoppel at the local Port Authority.

The supporting infrastructure for the collection of interisland trade data is inadequate and there is no comprehensive format reference or methode of inter-island trade data collection as factors that inhibit inter-island trade data collection. There is no legal policy or standard of format reference or methode that regulates systematically interisland trade data collection and reporting among agencies. The diversity of standard format reference or methode is mainly related to the guidance for name of item or type of goods and determination of units of volume or value so that data synchronization is difficult to attain.

\section{B. Analysis of the Effectiveness of Inter-island Trade Data}

The effectiveness of inter-island trade data collection using the IPA approach begins by determined the attributes which also come from identifying problems in inter-island trade data collections. The choice of attributes in the analysis of the effectiveness of inter-island trade data is shown in Table IV.

\section{TABLE IV. ATTRIBUTE OF THE EFFECTIVENESS OF INTER-} ISLAND TRADE DATA COLLECTION

\begin{tabular}{|c|c|}
\hline \multicolumn{2}{|r|}{ ATTRIBUTE } \\
\hline A & $\begin{array}{l}\text { The availability of clear information about the process of } \\
\text { reporting inter-island trade data collection }\end{array}$ \\
\hline B & There is a clear mechanism in reporting inter-island trade data \\
\hline $\mathrm{C}$ & There is a comprehensive method of inter-island data collection \\
\hline D & Ease in reporting inter-island trade data \\
\hline $\mathrm{E}$ & Inter-island trade data is available and easy to obtain \\
\hline $\mathrm{F}$ & $\begin{array}{l}\text { Human resources in inter-island trade data collection services } \\
\text { have good knowledge and understanding }\end{array}$ \\
\hline G & $\begin{array}{l}\text { Supporting infrastructure facilities on inter-island trade data } \\
\text { collection is adequate }\end{array}$ \\
\hline $\mathrm{H}$ & $\begin{array}{l}\text { The process of inter-island trade data collection does not take } \\
\text { long time }\end{array}$ \\
\hline 1 & $\begin{array}{l}\text { Socialization of the rules for inter-island trade data collection } \\
\text { has been carried out }\end{array}$ \\
\hline J & $\begin{array}{l}\text { Coordination between ministries and institutions in inter-island } \\
\text { trade data collections }\end{array}$ \\
\hline
\end{tabular}

Source: Processed Primary Data, 2018

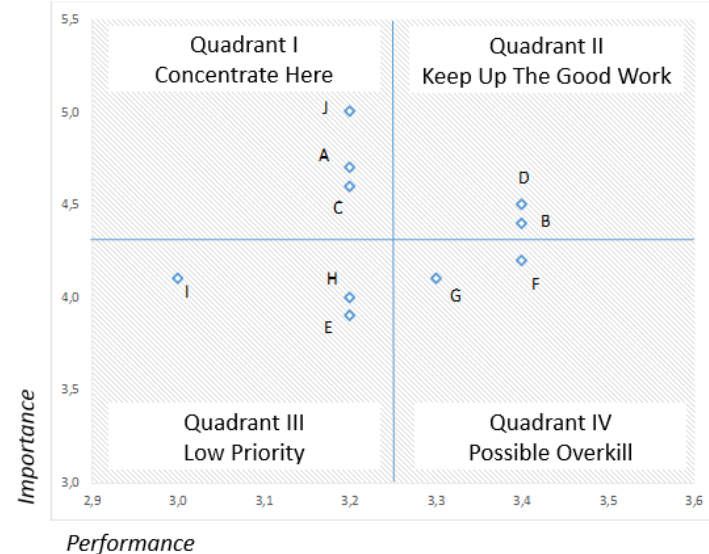

Source: Processed primary data, 2018

Fig. 3. Performance Collections Inter-island Trade Data Assessment

These attributes are then assessed by stakeholders with a questionnaire related to the level of importance and effectiveness of implementation. The results of IPA are shown in figure 3 . The result of IPA assessment obtained that in term of importance is at the level of 4.35. while in 
terms of performance is at the level of 3.25 and the index of IPA is at the level of $59.79 \%$. It can be interpreted that the importance and performances the process of inter-islands trade data collection is relatively acceptable.

The ten attributes of effectiveness of inter-island trade data collection then mapped in four quadrants to assess the performance of each of these attributes. Quadrant 1 Concentrate Here have three attributes, Quadrant II Keep Up the Good Work there are two attributes, Quadrant III Low Priority there are three attributes, and Quadrant IV Possible Overkill there are two attributes. The respective quadrants can be explained as follows:

- Quadrant I Concentrate Here: attributes in this quadrant are considered very important by stakeholders, but have not been satisfactory so the quality must be improved. The atribute namely coordination between ministries and institutions in collection inter-island trade data.

- Quadrant II Keep Up the Good Work: the attributes in this quadrant are considered very important and very satisfying, so the quality must be maintained. The atributes namely the ease of reporting inter-island trade data, and the clear mechanism and flow in reporting inter-island trade data.

- Quadrant III Low Priority: the attribute in this quadrant is considered to be insignificant and unsatisfactory. The atributes namely socialization of the rules for collecting inter-island trade data, the process of inter-island trade data collections does not take long time, and inter-island trade data is available and easy to obtain.

- Quadrant IV Possible Overkill: attributes in this quadrant are considered not important but satisfying. The atribute namely supporting infrastructure facilities in the inter-island trade data collections that is adequate and human resources in inter-island trade data collection services have good knowledge and good understanding.

Based on the results of the analysis, the government must focus more on improving the attributes included in Quadrant
I because these attributes are considered very important by stakeholders, but their performance is still not satisfactory. Meanwhile still maintaining performance on attributes that are considered to perform well, as covered in Quadrant II.

\section{CONCLUSIONS AND RECOMMENDATIONS}

In calculating the performance evaluation of inter-island trade data collection, the government must focus more on improving the attributes included in Quadrant I, which is coordination between Ministries and Institutions in interisland trade data collection, clear information on the stages of reporting inter-island trade data collection. This is because these attributes are considered very important by stakeholders, but their performance is still unsatisfactory, while still maintaining performance on attributes that are considered to be performing well, as included in Quadrant II, namely the ease of reporting inter-island trade data, and the mechanism is clear in reporting inter-island trade data collection.

Based on the results of the analysis, the proposed recommendations are the unification and uniformity of the method for collecting inter-island trade data is very important to obtain uniformity of data, especially related to the classification of types of goods and determination of units of volume or value. With this uniformity, inter-island trade data is easier to synchronize, although it is collected by different instituttions. In addition, the government needs to issue a legal policy equal to the Presidential Regulation to regulate the implementation and management of inter-island trade data.

\section{REFERENCES}

[1] C.L. Martinez, "Evaluation Report: Too is Cluster Networking Meeting \#1” Center Point Institute, Inc., Arizona. 2013

[2] D.R. Brandt, "An Outside-In Approach to Determining Customer Driven Priorities for Improvement and Innovation" White Paper Series, Volume 2-2000

[3] H. Boner, and D.A. Boone, "Analyzing Likert Data" Journal Extensions. Vol. 50 No. 2. April 2012. Article Number 2TOT2 